\title{
A Study on Spatial Accessibility of the Urban Tourism Attraction Emergency Response under the Flood Disaster Scenario
}

\author{
Yong Shi $\mathbb{D},{ }^{1,2}$ Jiahong Wen, ${ }^{3}$ Jianchao Xi $\mathbb{D}^{2}{ }^{2}$ Hui Xu, ${ }^{3}$ Xinmeng Shan, ${ }^{3}$ and Qian Yao ${ }^{4}$ \\ ${ }^{1}$ Department of Economics and Management, Shanghai University of Sport, Shanghai 200438, China \\ ${ }^{2}$ Institute of Geographic Sciences and Natural Research, Chinese Academy of Sciences, Beijing 100101, China \\ ${ }^{3}$ School of Environmental and Geographical Sciences, Shanghai Normal University, Shanghai 200234, China \\ ${ }^{4}$ School of Tourism Management, Zhengzhou University, Zhengzhou 450001, China \\ Correspondence should be addressed to Jianchao Xi; xijc@igsnrr.ac.cn
}

Received 8 May 2020; Revised 2 October 2020; Accepted 20 October 2020; Published 3 December 2020

Academic Editor: Jianhong (Cecilia) Xia

Copyright ( $\odot 2020$ Yong Shi et al. This is an open access article distributed under the Creative Commons Attribution License, which permits unrestricted use, distribution, and reproduction in any medium, provided the original work is properly cited.

\begin{abstract}
With the ultrahigh-speed, large-scale development of tourism and the increasing frequency, intensity, and scope of extreme natural hazards in the context of climate warming, tourism has entered a high-risk era. Based on the central urban area within the outer ring of Shanghai as the research area and the tourism attraction as the research object, this paper takes the flood scenario simulation combined with GIS network analysis to evaluate the spatial accessibility of the emergency response of urban key public service departments (120) under current and future river flood scenarios in different return periods. The results of the study show that, (1) under the current and future flood scenarios, the submergence range is mainly distributed within $2 \sim 3 \mathrm{~km}$ along the banks of the Huangpu River, and it tends to increase from north to south; (2) there are 6, 9, and 21 tourism attractions in the emergency blind area under the once-in-a-century floods in 2010, 2030, and 2050 and 98, 105, and 112 tourism attractions in the emergency blind area under the once-in-a-millennium floods in 2010, 2030, and 2050, respectively; (3) in the flood scene, local road traffic in the inundation area is interrupted by water, and 120 first aid cannot get or be delayed to some tourist attraction (blind area); and (4) in 2030, under the normal and flooding scenarios, 120 first aid in the downtown area of Shanghai has the fastest route to tourism attractions according to the speed of S1, S2, S3, and S4. The flooding intensity (range and water depth), road traffic conditions (vehicle flow speed), and the number and location of key public service departments jointly determine the service scope and response time of medical emergency in urban floods. Since the flood control area of the central city in Shanghai is mainly distributed in the $2 \sim 3 \mathrm{~km}$ area on both banks of the Huangpu River, the impact of flood on the emergency medical service in the entire central city is limited, mainly in some hospitals in the riverside area, where 120 emergency vehicles are unable or delayed to reach some tourism attractions. The research indicates that the quantitative assessment method of spatial accessibility of the emergency response under flood scenario simulation has important scientific value and practical significance, which can provide decision-making basis for emergency management of tourism in China's urban flood disaster.
\end{abstract}

\section{Introduction}

Tourism has entered a high-risk era. First of all, it originated from the ultrahigh-speed and large-scale development of tourism. In 2018, the national tourism industry's comprehensive contribution to GDP has reached $11.04 \%$, tourism direct and indirect employment accounted for $10.29 \%$ of the country's total employment population, and the number of domestic tourists and outbound tourists and their consumption have ranked first in the world; thus, the tourism has become a veritable strategic pillar industry. Secondly, with the global warming and the increasing frequency, intensity, and impact of extreme natural hazards, about 1,000 scenic spots above 3A level in China are affected by natural hazards of different degrees each year, accounting for $60 \%$ of the country. In recent years, the occurrence of a series of tourism safety accidents led by the Jiuzhaigou earthquake has made tourism safety management and risk warning work even more urgent. Especially on the eastern coast, tourism and overall economic development are far superior 
to the central and western regions. However, due to the special zone at the junction of the land and sea, the most direct threat caused by the global warming is the increase of extreme hazards such as storm floods [1]. In addition to causing serious house collapse and casualties, it also brings indirect effects such as road traffic disruption, reduced service scope of public facility services, and delays in emergency response time [2]. Tourism is very sensitive to natural hazards. Natural hazards lead to safety incidents, which not only affect the tourism experience but also damage the image of the scenic spot and restrict the development of tourism.

In this context, recent research has made progress in determining the impact of natural hazards on tourism [3-8]; especially in coastal areas, sea level rise and storm surges cause frequent social and economic losses [9-14]. Scott et al. [6] demonstrated that a number of previous research studies had explored the effects of sea level rise on coastal tourism around the world (such as floods and erosion), with particular emphasis on the vulnerability of tourism infrastructure and coastal resources (primarily beaches). Kellens et al. [15] quantified the impact of storm surges on the casualties and behavior of tourists on the Belgian coast.

The implementation of the International Strategy for Disaster Reduction in recent years has shown that the efficient improvement of the emergency response capability of public service facilities is the most powerful guarantee to reduce the direct and indirect impacts of tourism caused by floods. Especially in cities, tourism disaster management and prevention work are of great significance to the current national scientific front and the development of national need. At present, the research on the urban emergency response ability in floods mainly focuses on the theory and planning level [16], but it lacks cases that combine flood simulation results with the traffic network to evaluate the emergency response capacity of public service facilities (medical treatment, public security, firefighting, etc.) in the face of nature hazards in urban tourism. Within this paper, taking the city center of Shanghai as the research area, in view of the tourism attractions of the region (that is, the tourism attractions), we used network analysis tools in ARCGIS, combined with the simulation results drawn by the Huangpu River floods and the road network in the study area, to carry out accessibility of the urban public safety emergency response space in normal and flood scenarios of different return periods, so as to enrich the urban flood disaster risk assessment and management system and provide scientific basis for tourism disaster prevention and mitigation.

\section{Research Data and Methods}

2.1. General Situation of the Research Region. The central city within the outer ring of Shanghai is located in the middle and lower reaches of the Huangpu River, with a total area of about $666 \mathrm{~km}^{2}$. It is a political, economic, and cultural center of Shanghai and a typical flood-prone area (Figure 1). The terrain in the region is low and flat, with an average altitude of only about 3-4 $\mathrm{m}$ (Wusong elevation). In some areas, the surface elevation is even lower than the average high-water level for many years, and the self-drainage condition is lost. In addition, due to long-term, high-intensity human activities, the number of people involved in the disaster has increased, the natural rivers in the central city have been significantly reduced, the surface of the impervious land has increased rapidly, and the ground has been seriously settled (maximum over $3 \mathrm{~m}$ ). The "amplification effect" is extremely significant $[17,18]$.

Shanghai suffers from typhoons and heavy rains in different degrees every year. In the flood season, the astronomical tide, typhoon, interval rainstorm, and floods in the upper reaches of Taihu Lake meet fortuitously [19].

Historically, flood disasters occurred frequently in the central area of Shanghai. According to incomplete statistics, more than 500 flood disasters occurred from AD 251 to 2000 [20]. In order to prevent floods, Shanghai has built and expanded the flood control wall system along the Huangpu River since the 1950s, in which the city section can withstand the once-in-a-century flood scenario (1984 design standard). However, with the impact of sea level rise and land subsidence, the actual fortification capacity of the flood control wall has been greatly reduced [21, 22]. The inner city of Shanghai involves 7 districts (administrative units) including Yangpu District (38 tourism attractions), Hongkou District (49 tourism attractions), Huangpu District (141 tourism attractions), Jing'an District (58 tourism attractions), Putuo District (36 tourism attractions), Xuhui District (71 tourism attractions), and Changning District (35 tourism attractions). There are 428 tourism attractions reflecting the urban development in the downtown area of Shanghai, most of which are cultural attractions, including buildings and facilities. In the process of eclecticism and fusion of west and east, the culture is inclusive, and Shanghai has been a unique "World Architecture Expo." Celebrity culture is the flash point of Shanghai, especially Hengshan Road-Fuxing Road Historical and Cultural Area and Shanyin Road Historical and Cultural Area. In Shanghai, red tourism culture has also been excavated and protected, and there are many red tourism attractions, forming a distinctive cultural tourism atmosphere.

2.2. Research Data. The data involved in this research include flood submergence simulation results, road network traffic data, urban public service facility data, and spatial distribution data of tourism attractions. The simulation results adopted inundation areas and depths in the once-ina-century and once-in-a-millennium flood scenarios (in 2010, 2030, and 2050, mainly with different sea level heights) of the Huangpu River basin obtained from previous studies $[23,24]$ and screened the flooded areas in the city center of Shanghai. The data of the road network and urban public service facilities are from the 2013 Shanghai Traffic (Amap) navigation data set from GIS. According to the research needs, the road network data of the central urban area are cut out, which contain about 102,000 sections. The property list contains basic information such as road name, function, and length but lacks necessary information such as direction, 


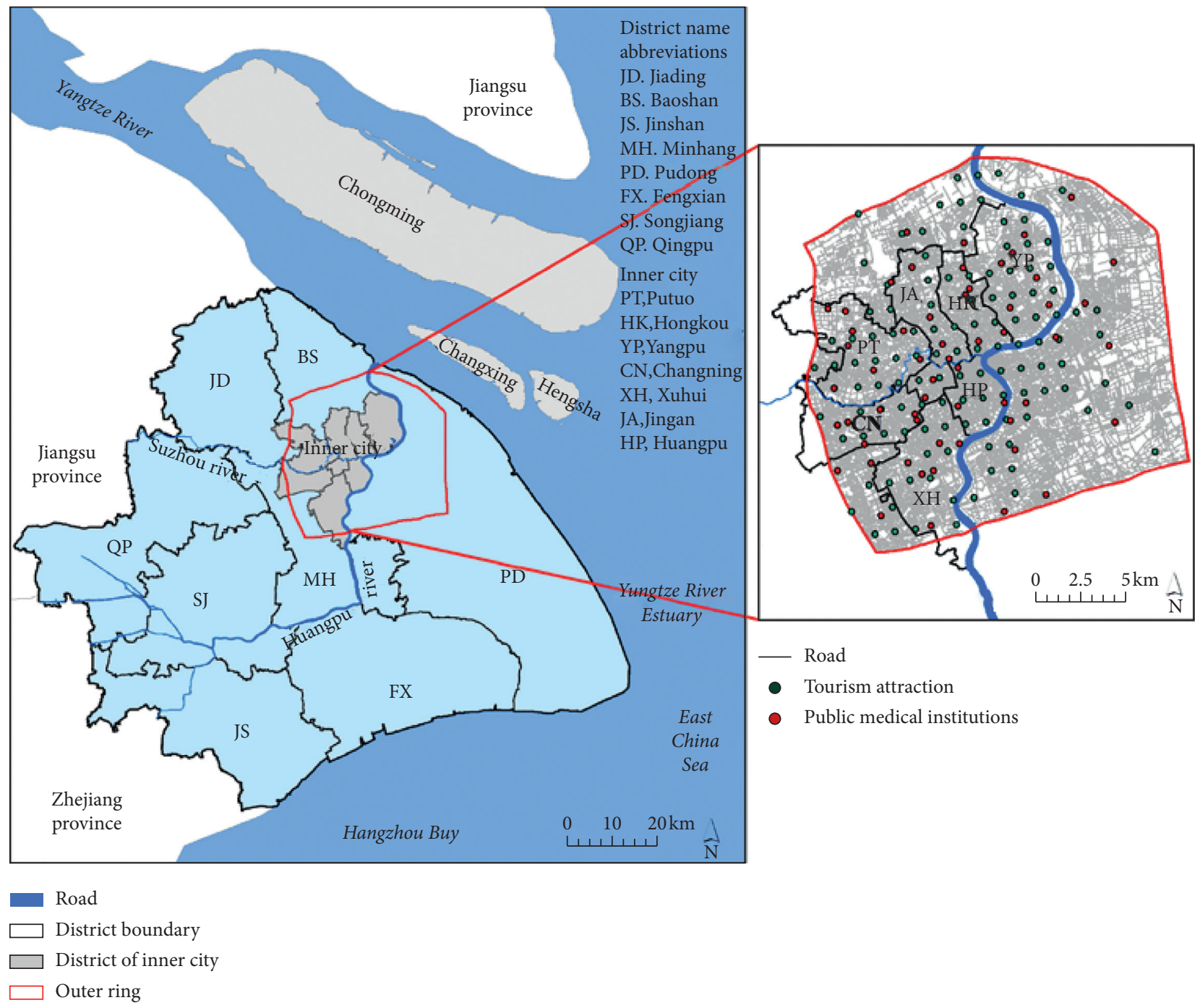

(a)

(b)

FIGURE 1: Location of the research area.

road grade, and speed limit. Therefore, road network data should be further processed. We should load the road network data in ArcGIS 10.2 software, refer to the traffic directions of Google Maps, add the attribute list of road direction, and point out the odd or double direction settings. Referring to the "Technical Standard of Highway Engineering (JTG B01-2003)" and combining the actual road conditions in Shanghai, the roads are divided into five grades, and the maximum speed limit is set to $120 \mathrm{~km} / \mathrm{h}$ for the expressway, $80 \mathrm{~km} / \mathrm{h}$ for the freeway, $60 \mathrm{~km} / \mathrm{h}$ for the main road, $50 \mathrm{~km} / \mathrm{h}$ for the secondary road, and $30 \mathrm{~km} / \mathrm{h}$ for the branch road. Urban public service facilities mainly include emergency response departments and public service agencies. This study selected 120 emergency centers and vulnerable tourism attractions in the city as the key research object of emergency response service in floods. Through the screening of the original data, 146 public medical institutions above the second level with emergency capability and 486 tourism attractions were retained as research objects.

\subsection{Research Methods}

2.3.1. Flood Numerical Simulation. This study used a wellestablished flood inundation model $[25,26]$. The model coupled a 1D full solution of the Saint-Venant equation for river flow and a 2D diffusion-based flood inundation model on the floodplain. The model has a similar model structure and governing equations as LISFLOOD-FP and JFLOW and is the current international mainstream flooding numerical simulation technology. The model solves the one-dimensional St. Venant equations for unsteady flow using the Preissmann scheme. The respective mass and momentum conservation forms of the equations are

$$
\begin{aligned}
& \frac{\partial h}{\partial t}+h \frac{\partial u}{\partial x}+u \frac{\partial h}{\partial x}=0, \\
& \frac{\partial u}{\partial t}+u \frac{\partial u}{\partial x}+g \frac{\partial h}{\partial x}=g S_{0}-g S_{f},
\end{aligned}
$$


where $h$ is the water depth, $u$ is the velocity, $x$ is the increment over space, $t$ is the increment over time, $g$ is the acceleration due to gravity, $S_{0}$ is the local bed slope, and $S_{f}$ is the slope of the energy grade line.

The 2D floodplain flow model is developed based on the discretization of Manning's equation over a regular grid. The structure of the model has been described in Yu and Lane (2006a); therefore, only the major model structure is presented here. Although the hydrodynamic condition is simplified, it has the advantages of simple operation, high computational efficiency, and high simulation accuracy. Flux in a diffusion-based flood inundation model can be determined using Manning's equation whilst ignoring the inertial and advection forces of the flow. Manning's equation expressed for parameters in a regular computational mesh takes the form

$$
Q=\frac{w d^{(5 / 3)} S^{(1 / 2)}}{n},
$$

where $Q$ is the flux out of a grid cell, $w$ is the mesh resolution, $d$ is the effective flow depth, $S$ is the energy slope, and $n$ is Manning's roughness coefficient. The model parameters are based on the empirical coefficients determined by the previous research: riverbed roughness $0.03 \sim 0.05$, land roughness 0.06 , time step $10 \mathrm{~s}$, and one-dimensional model calculation results (channel process water level) as the boundary condition of the two-dimensional simulation, and the simulation time is set to 12 hours before and after the highest tide appeared, simulating the once-in-a-century and once-in-a-millennium floods in the 2010s, 2030s, and 2050s (different sea level elevations).

2.3.2. Identification of Flooded Scenic Spots. According to the location of tourism attractions in the central city of Shanghai, the simulated water depth distribution map of flood disasters and the distribution map of tourism attractions in the area are superimposed, and the superposition of tourism attractions and disaster depth in the Shanghai central city area is obtained. The layer can distinguish the inundation depth of various tourist attractions under the action of flood disasters.

\subsubsection{Identification of Flooded Roads and Emergency Blind} Areas. In the event of sudden hazards, it is often necessary for 120 emergency vehicles to travel from hospitals to the accident site for treatment and rescue. However, in the flood scene, when the road water reaches $25 \sim 35 \mathrm{~cm}$ (the height of the vehicle exhaust port), the vehicle cannot pass safely. When the roads around the tourism attraction are submerged by floods exceeding $30 \mathrm{~cm}, 120$ rescue vehicles could not be reached, and the tourism attraction becomes an emergency blind area (Figure 2). No measures could be taken to rescue solely on the ground.

2.3.4. Emergency Shortest Path. In addition to spatial accessibility based on the road network analysis, the key indicators for evaluating the disaster emergency response capacity of urban public services (such as 120 first aid) include the shortest path. For tourism attractions out of the blind area, 120 emergency vehicles are required to take the shortest path and reach the accident site within the shortest time (the international standard is the best rescue time within $8 \sim 10 \mathrm{~min}$ ) in the flood situation where they have to make a detour.

This paper adopts the fastest path algorithm based on GIS network analysis (the time between two points is the shortest), does not consider the constraints of urban road traffic rules (such as traffic lights and turn signals), sets the upper limit of water depth of accessible roads to $30 \mathrm{~cm}$, with each hospital location as a starting point, and thus finds out the quickest path to tourism attractions.

Referring to the "Code for Transport Planning on Urban Road (GB50220-95)," considering the maximum speeds of different classes of roads and different speeds of vehicles in the city during evenings and weekends, daytime, and commuting peak, and referring to the real-time traffic analysis report of Shanghai in the Amap, the speed is set to the maximum speed limit S1, S2, S3, and S4 (Table 1), respectively, so as to cover all possible urban road traffic conditions and to calculate the shortest path from hospitals to tourism attractions for 120 first aid under normal conditions and the flooding scenario, respectively.

\section{Result Analysis}

3.1. Flood Submergence and Exposure Analysis. The simulation results of the maximum submergence range and depth of floods in downtown Shanghai are shown in Figure 3, which mainly show the following characteristics: as the elevation of topography and the flood control wall decrease gradually from north (the lower reaches of the Huangpu River) to south (the middle and lower reaches), the flood submergence range and submergence depth gradually increase from north to south; due to the role of the flood control wall, the flood submergence area of the Huangpu River is mainly distributed within $2 \sim 3 \mathrm{~km}$ along the banks of the river, and the farther the flooding from the river is, the smaller the depth is; as the sea level rises, the flooding extent and submergence depth will increase significantly in 2030 and 2050. In the once-in-a-century flood scenario, the submergence area gradually expanded to the entire central urban area along the river, but the depth of submergence was shallow (not more than $30 \mathrm{~cm}$ ), and the affected sections were relatively small, mainly distributed in Huangpu District, Xuhui District, and Pudong New Area along the Yangtze river. In the once-in-a-century flood submergence scenario, most sections of the flood submergence area have accumulated more than $30 \mathrm{~cm}$ of water, and some key areas (such as Lujiazui Financial Zone and Nanjing East Road CBD) have accumulated more than $1 \mathrm{~m}$ of water. This not only directly threatens the public service facilities in the flood submergence area but also may seriously affect the normal traffic of the road network along the river (especially, the river passage). As a result, the emergency rescue services on both sides of the Huangpu River have been interrupted or delayed. 


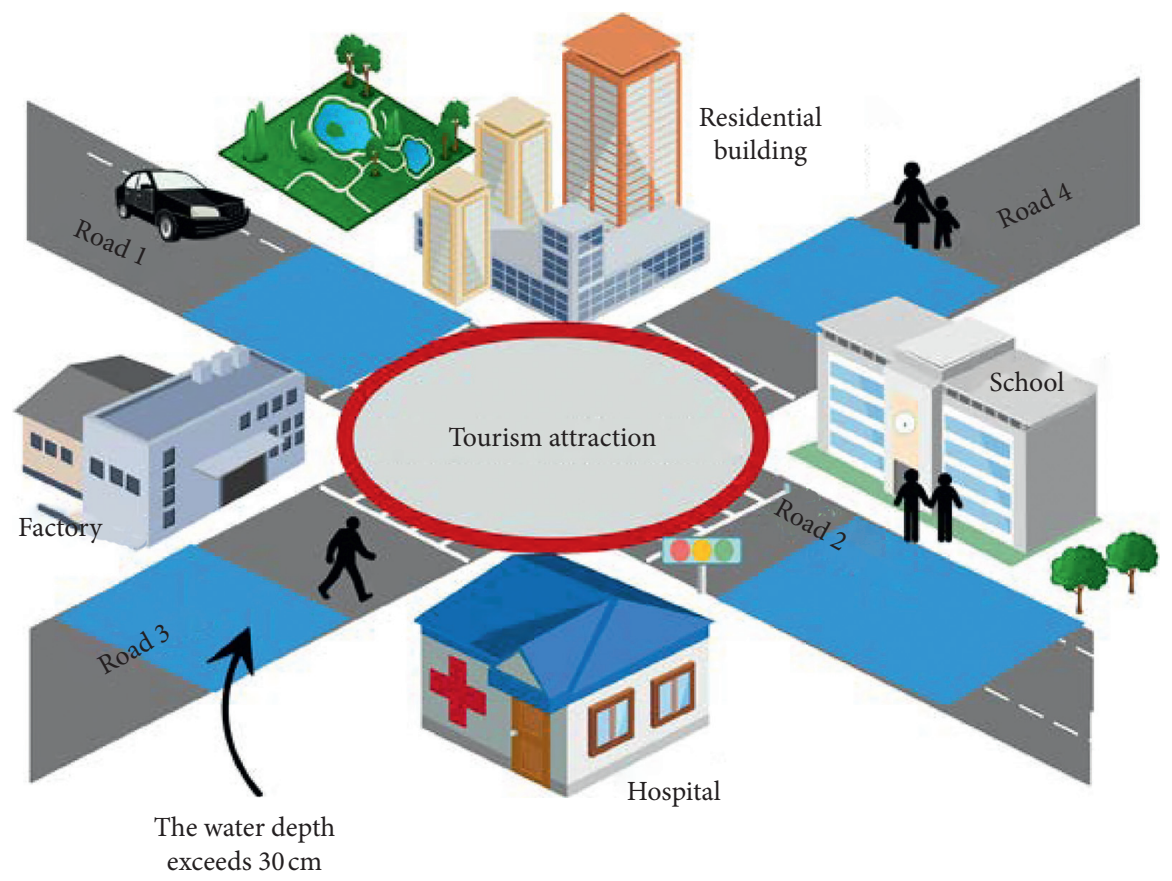

FIgURE 2: Tourism attraction in the emergency blind area.

TABLE 1: Maximum speed limit in different classes of roads and speeds in different conditions.

\begin{tabular}{|c|c|c|c|c|c|}
\hline Type & Elevated road & Expressway & Main road & Secondary road & Branch road \\
\hline S1 (maximum speed limit) & 120 & 80 & 60 & 50 & 30 \\
\hline S2 (evening and weekend) & $1 / 3 \mathrm{~S} 1$ & $1 / 3 \mathrm{~S} 1$ & $1 / 3 \mathrm{~S} 1$ & $1 / 3 \mathrm{~S} 1$ & $1 / 2 \mathrm{~S} 1$ \\
\hline S3 (daytime) & $1 / 4 \mathrm{~S} 1$ & $1 / 3 \mathrm{~S} 1$ & $1 / 4 \mathrm{~S} 1$ & $1 / 3 \mathrm{~S} 1$ & $1 / 2 \mathrm{~S} 1$ \\
\hline S4 (commuting peak) & $1 / 4 \mathrm{~S} 1$ & $1 / 3 \mathrm{~S} 1$ & $1 / 5 \mathrm{~S} 1$ & $1 / 5 \mathrm{~S} 1$ & $1 / 3 \mathrm{~S} 1$ \\
\hline
\end{tabular}

According to the simulation results of the maximum flooding range and depth in downtown Shanghai and the spatial distribution of tourism attractions, it can be seen that 26,36 , and 46 tourism attractions were flooded in 2010, 2030, and 2050 under the once-in-a-century flooding disasters, respectively, and under the once-in-a-millennium floods in 2010, 2030, and 2050, respectively; there were 97, 127 , and 188 inundated tourism attractions under waterlogging disasters.

\subsection{Emergency Blind Area Analysis. The Network Dataset} tool in ArcGIS is used to construct the topological relationship of the traffic network, and the built network is loaded into the map layer. The function of New Service Area in the Network Analyst tool is used to load 120 first-aid points and the sections whose water depth exceeds $30 \mathrm{~cm}$ into the service domain analysis as facility points and line obstacles, so as to calculate the service range of 120 first aid under normal and different flooding scenarios. Because of road flooded, 120 ambulances cannot reach some tourism attractions in any way, that is, the emergency blind area. According to the operation, there are 6, 9, and 21 tourism attractions in the emergency blind area under the once-in-acentury floods in 2010, 2030, and 2050 and 98, 105, and 112 tourism attractions in the emergency blind area under the once-in-a-millennium floods in 2010, 2030, and 2050, respectively.

3.3. Emergency Shortest Path. Because tourists are not familiar with the surrounding environment and the irreplaceable value of tourism attractions, which are often located in areas with the most serious impact of urban floods, emergency relief is particularly important. Aiming at this problem, this study calculated the fastest route of 120 first aid to tourism attractions according to the speed of S1, S2, S3, and S4 in the downtown area of Shanghai in 2030 under normal and once-in-a-century and once-in-a-millennium flood submergence scenarios, respectively (Figure 4).

Under normal traffic condition S1 without floods, 120 ambulances need an average of about 3.56 minutes to reach all tourism attractions in the central city, and the slowest response time is 12.12 minutes. In flood submergence scenarios, affected by the local road blockade, some tourism attractions cannot be reached, and emergency response time of some rescue points has been delayed. The response time of 477 tourism attractions arrived in 2030 was delayed by $1.86 \mathrm{~min}$ (under $\mathrm{S} 1$ ), respectively, in the case of once-in-acentury flooding. In the case of once-in-a-millennium flooding, the number of affected rescue sites increased 
2010 once in a century

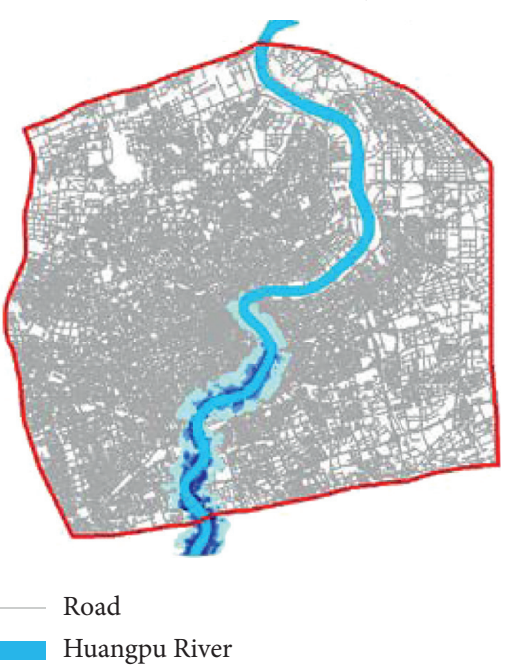

2010 once in a millennium

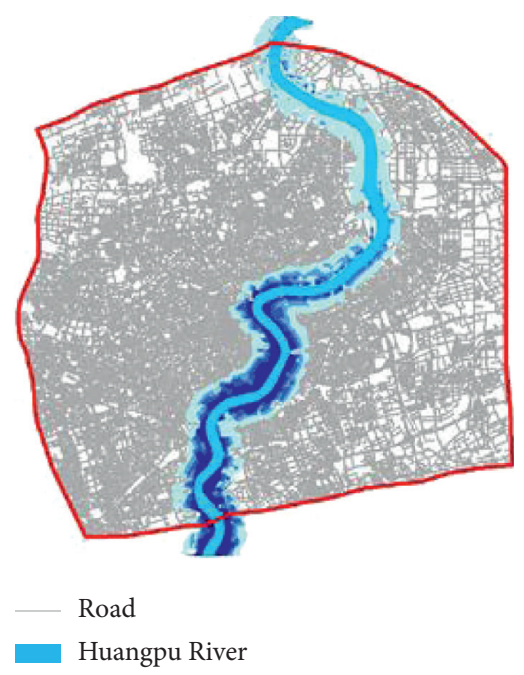

2030 once in a century
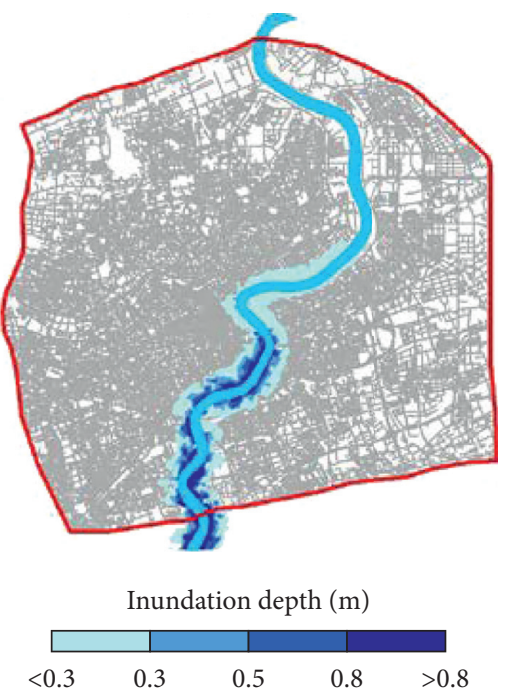

2030 once in a millennium
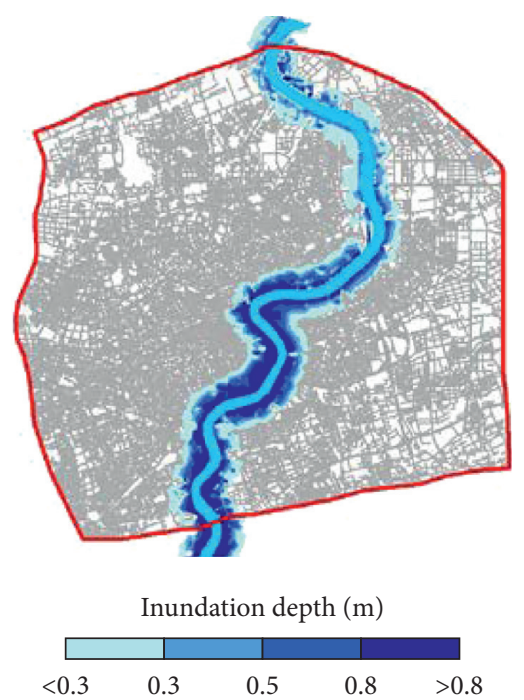

2050 once in a century
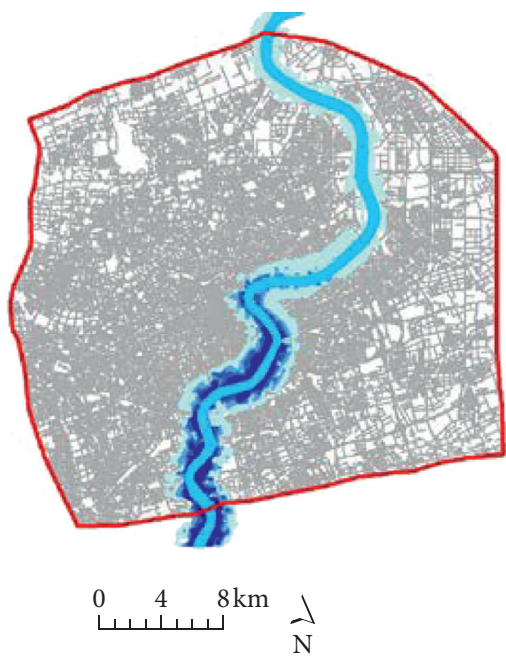

2050 once in a millennium
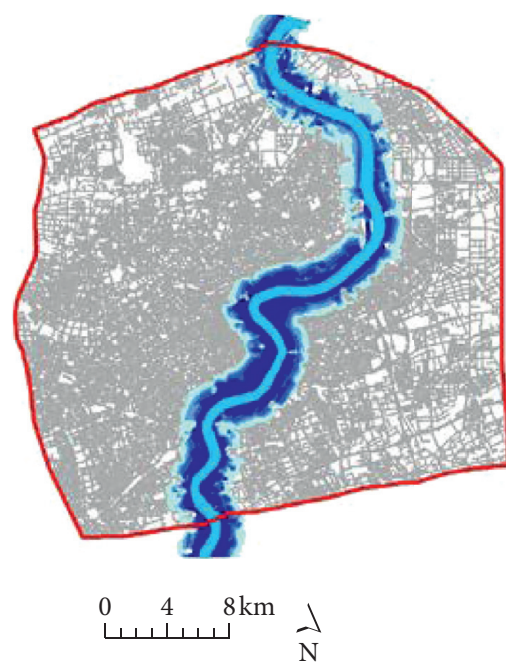

Figure 3: Inundation extents and depths for flood scenarios in the city center of Shanghai.

significantly. The response time of 381 tourism attractions arrived in 2030 was delayed by 0.96 minutes (under the S1 condition), and the maximum delay time was more than 6 minutes. However, under the conditions of S2, S3, and S4, the delay time of the emergency response will be doubled. Although the flood impact in the central city is limited to the area along the Huangpu River, the impact of the tourism industry is still very significant since the tourism attractions in the central city of Shanghai are mainly distributed on the banks of the Huangpu River in Yangpu District and Huangpu District.

3.4. Discussion of Countermeasures. In view of the significant impact of floods on the tourism industry, the urban emergency management department needs to take effective measures to ensure the accessibility of the key nodes and sections of the road network and the accessibility of emergency first-aid services. First, we should improve the defense capacity of urban flood control walls along rivers, rationally plan the spatial distribution of drainage networks along the Yangtze River, and increase the number of rainwater wells and drainage capacity in waterlogging-prone streets. Secondly, we should rationally plan and lay out the main emergency response departments of the city. For tourism attractions located in the heavily inundated areas, we should set up early warning and equip with refuge materials to reduce vulnerability. Thirdly, we should increase the emergency rescue vehicles and other rescue equipment (such as helicopters and collapsible hovercrafts) of the city's key public service facilities and enhance their rescue capacity. 

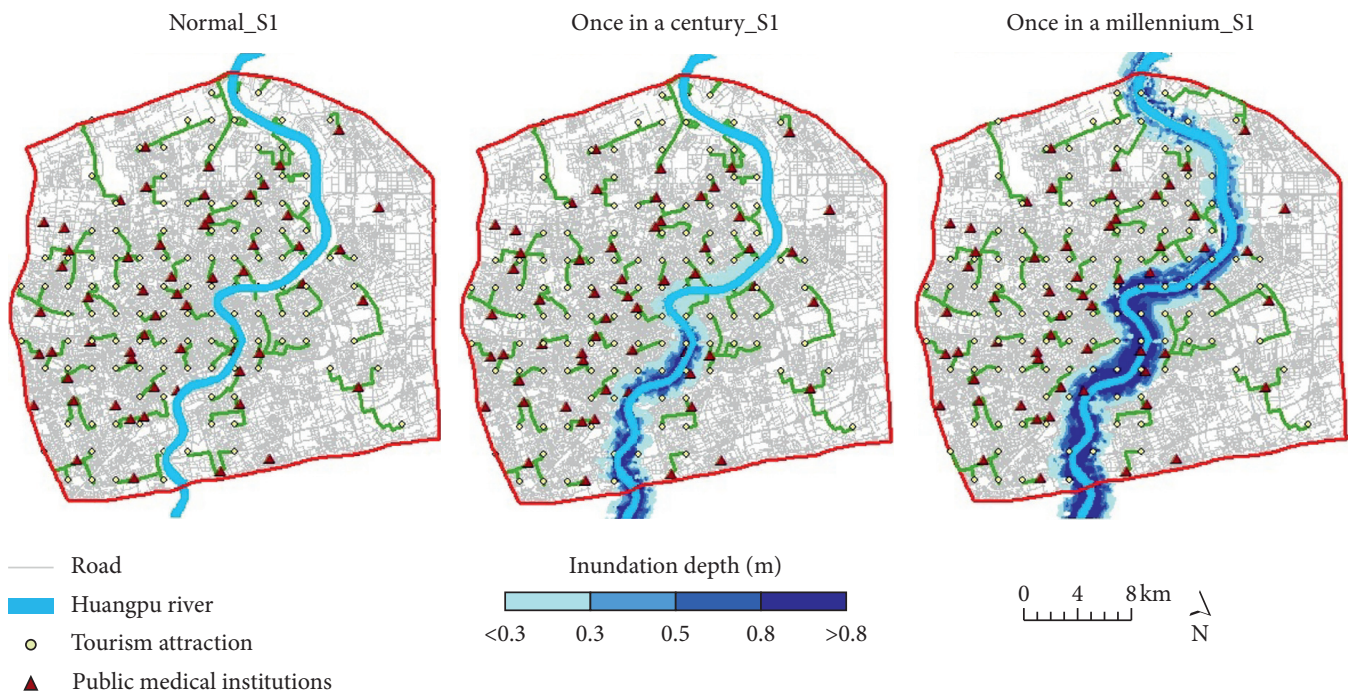

\ Public medical institutions
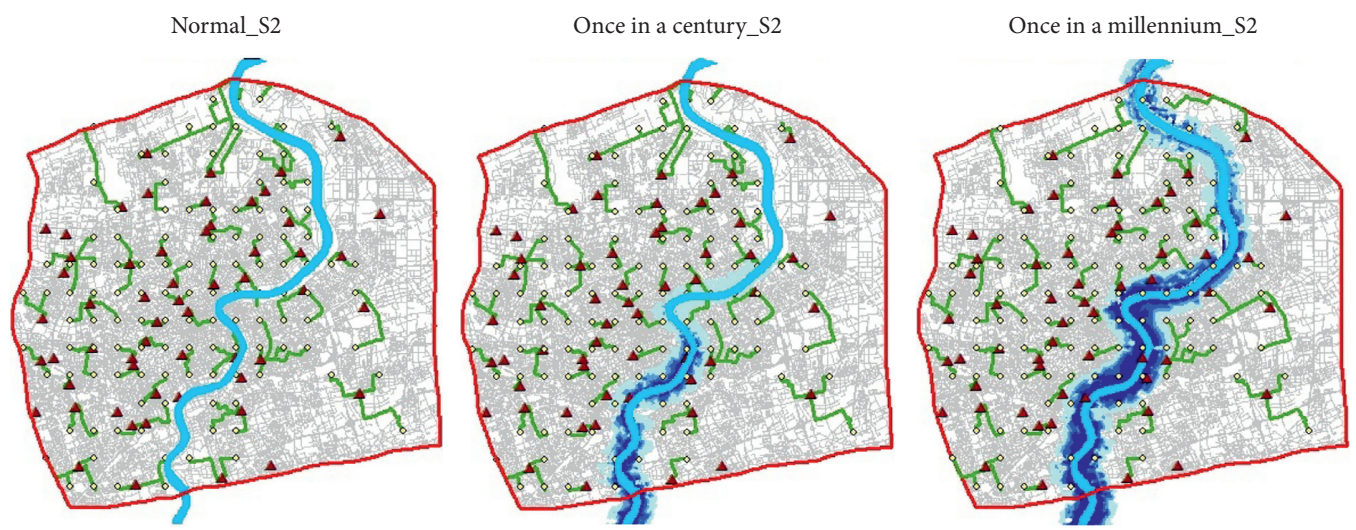

Road
Huangpu river
○ Tourism attraction
$\Delta \quad$ Public medical institutions
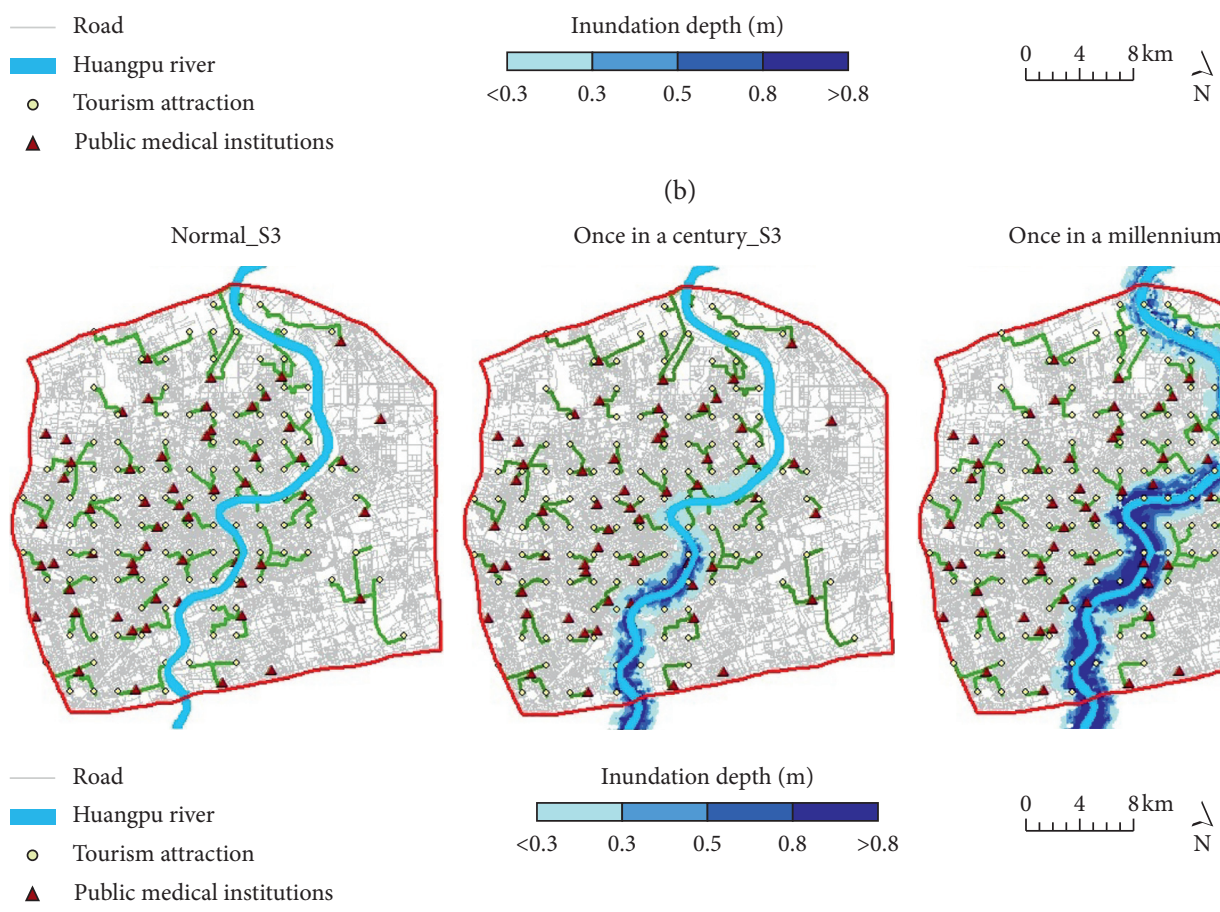

(b)
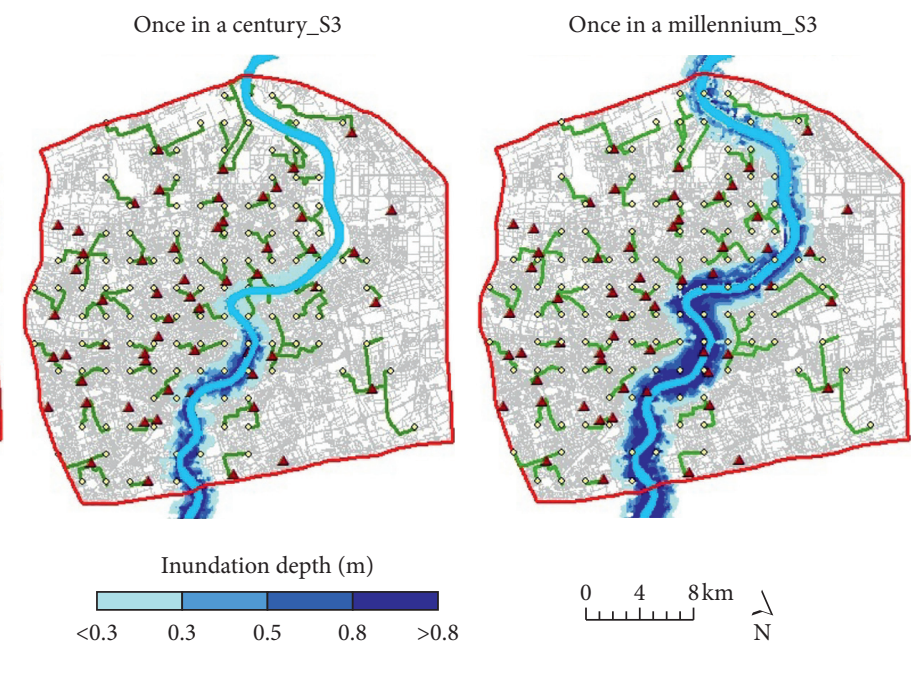

(c)

FIgure 4: Continued. 


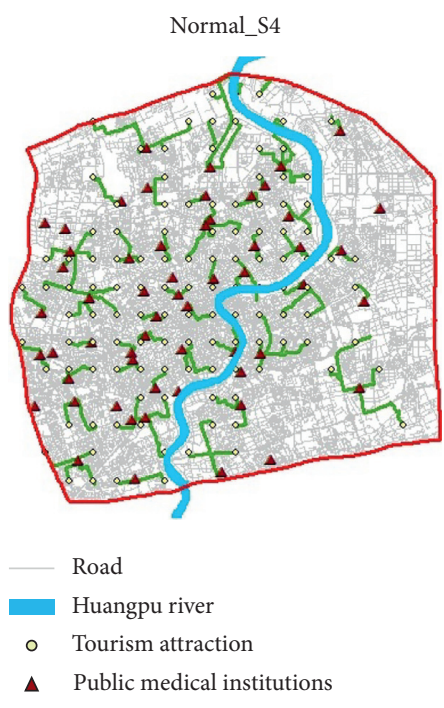

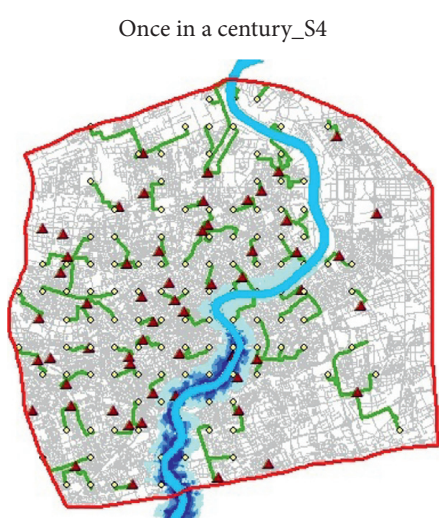

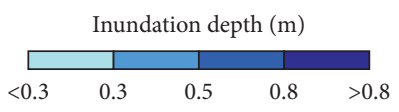

(d)

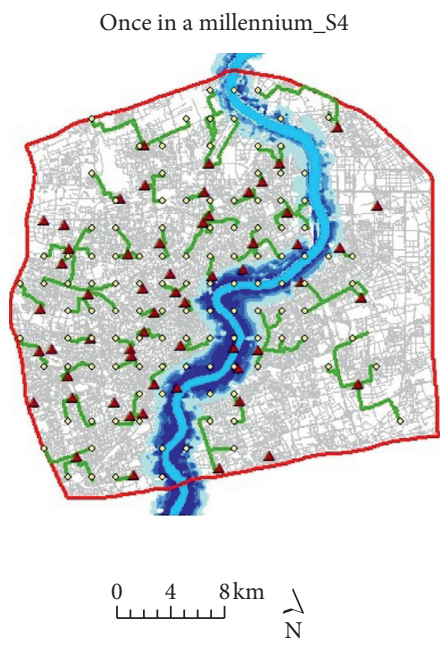

FIgURE 4: Closest facility analysis for public medical institutions to tourism attractions under normal conditions and flood scenarios in 2030.

\section{Conclusion and Prospect}

In this paper, numerical simulation and GIS network analysis are used to evaluate the spatial accessibility of 120 emergency responses to tourism attractions in downtown Shanghai under normal conditions and once-in-a-century and once-in-a-millennium flood scenarios, providing typical cases and research models for urban tourism emergency management. The results show that, under the current and future flood scenarios, the submergence range is mainly distributed within $2 \sim 3 \mathrm{~km}$ along the banks of the Huangpu River, and it tends to increase from north to south; there are 6,9 , and 21 tourism attractions in the emergency blind area under the once-in-a-century floods in 2010, 2030, and 2050 and 98,105 , and 112 tourism attractions in the emergency blind area under the once-in-a-millennium floods in 2010, 2030, and 2050, respectively; in the flood scene, local road traffic in the inundation area is interrupted by water, and 120 first aid cannot get or be delayed to some tourist attraction (blind area); and in 2030, under the normal and flooding scenarios, 120 first aid in the downtown area of Shanghai has the fastest route to tourism attractions according to the speed of S1, S2, S3, and S4. This paper is only a preliminary discussion on the impact of river flooding on the public safety emergency response capability of urban tourism. The future research work can be further deepened and expanded in the following aspects: (1) in addition to flood depth, the flood duration and flow rate should be considered for the impact of urban flood on the capacity of road traffic and emergency service facilities in the tourism industry; (2) urban traffic big data (such as taxi track and speed data) should be introduced to provide urban road network traffic (speed) with more realistic spatial-temporal observation and simulation data; and (3) this research focused on the inundate effects of river floods on tourism attractions, and the follow-up work can further deepen the planning and research on the postdisaster emergency evacuation (the location of the refuge and the optimal evacuation route selection) of the submerged tourism attractions.

\section{Data Availability}

The data used in this paper are taken from the government statistical yearbook.

\section{Conflicts of Interest}

The authors declare no conflicts of interest.

\section{Acknowledgments}

This research was funded by the Humanities and Social Sciences Plan Project of Henan Provincial Education Department (Grant no. 2020-ZZJH-457), the Key Laboratory of Regional Sustainable Development Modeling, Institute of Geographic Sciences and Natural Resources Research, Chinese Academy of Sciences (Grant no. KF2018-06), the National Natural Science Foundation of China (Grant nos. 41601566, 41601568, 41671151, 41771540, and 71603168), the Humanities and Social Sciences Project of Education Ministry (Grant no. 14YJCZH128), and National Key Research and Development Program (Grant no. 2018YFC0406505).

\section{References}

[1] IPCC, Climate Change 2007: The Physical Science Basis. Contribution of Working Group I to the Fourth Assessment Report of the Intergovernmental Panel on Climate Change, pp. 95-123, Cambridge University Press, Cambridge, UK, 2007.

[2] Y. F. Liao, C. J. Nie, L. S. Yang, and H. R. Li, "An overview of the risk assessment of flood disaster," Progress in Geography, vol. 31, no. 3, pp. 361-367, 2012, in Chinese. 
[3] C. Schleupner, "Evaluation of coastal squeeze and its consequences for the Caribbean island Martinique," Ocean \& Coastal Management, vol. 51, no. 5, pp. 383-390, 2008.

[4] A. Moreno and B. Amelung, "Climate change and coastal \& marine tourism: review and analysis," Journal of Coastal Research, vol. 56, pp. 1140-1144, 2009.

[5] S. L. Perch-Nielsen, "The vulnerability of beach tourism to climate change-an index approach," Climatic Change, vol. 100, no. 3-4, pp. 579-606, 2010.

[6] D. Scott, M. C. Simpson, and R. Sim, "The vulnerability of Caribbean coastal tourism to scenarios of climate change related sea level rise," Journal of Sustainable Tourism, vol. 20, no. 6, pp. 883-898, 2012.

[7] K. Sagoe-Addy and K. A. Addo, "Effect of predicted sea level rise on tourism facilities along Ghana's Accra coast," Journal of Coastal Conservation, vol. 17, no. 1, pp. 155-166, 2013.

[8] T.-A. Hyman, "Assessing the vulnerability of beach tourism and non-beach tourism to climate change: a case study from Jamaica," Journal of Sustainable Tourism, vol. 22, no. 8, pp. 1197-1215, 2014

[9] S. Hallegatte, N. Ranger, O. Mestre et al., "Assessing climate change impacts, sea level rise and storm surge risk in port cities: a case study on Copenhagen," Climatic Change, vol. 104, no. 1, pp. 113-137, 2011.

[10] H. Brecht, S. Dasgupta, B. Laplante, S. Murray, and D. Wheeler, "Sea-level rise and storm surges," The Journal of Environment \& Development, vol. 21, no. 1, pp. 120-138, 2012.

[11] A. A. Mather and D. D. Stretch, "A perspective on sea level rise and coastal storm surge from southern and eastern Africa: a case study near Durban, South Africa," Water, vol. 4, no. 1, pp. 237-259, 2012.

[12] A. Khouakhi, M. Snoussi, S. Niazi, and O. Raji, "Vulnerability assessment of Al Hoceima bay (Moroccan Mediterranean coast): a coastal management tool to reduce potential impacts of sea-level rise and storm surges," Journal of Coastal Research, vol. 65, pp. 968-973, 2013.

[13] A. Murdukhayeva, P. August, M. Bradley, C. LaBash, and N. Shaw, "Assessment of inundation risk from sea level rise and storm surge in northeastern coastal national parks," Journal of Coastal Research, vol. 291, pp. 1-16, 2013.

[14] J. E. Neumann, K. Emanuel, S. Ravela et al., "Joint effects of storm surge and sea-level rise on US coasts: new economic estimates of impacts, adaptation, and benefits of mitigation policy," Climatic Change, vol. 129, no. 1-2, pp. 337-349, 2015.

[15] W. Kellens, T. Neutens, P. Deckers, J. Reyns, and P. D. Maeyer, "Coastal flood risks and seasonal tourism: analysing the effects of tourism dynamics on casualty calculations," Natural Hazards, vol. 60, no. 3, pp. 1211-1229, 2012.

[16] Defra, The National Flood Emergency Framework for England, Environment Agency, London, UK, 2014.

[17] S. L. Gong and S. L. Yang, "Effect of land subsidence on urban flood prevention engineering in Shanghai," Scientia Geographica Sinica, vol. 28, no. 4, pp. 543-547, 2008, in Chinese.

[18] X. Wu, D. Yu, Z. Chen, and R. L. Wilby, "An evaluation of the impacts of land surface modification, storm sewer development, and rainfall variation on waterlogging risk in Shanghai," Natural Hazards, vol. 63, no. 2, pp. 305-323, 2012.

[19] X. T. Liu, Shanghai Flood Prevention Handbook, Shanghai Popular Science Press, Shanghai, China, 2008, In Chinese.

[20] R. Quan, "Risk assessment of flood disaster in Shanghai based on spatial-temporal characteristics analysis from 251 to 2000," Environmental Earth Sciences, vol. 72, no. 11, pp. 4627-4638, 2014.
[21] J. Yin, D. Yu, Z. Yin, J. Wang, and S. Xu, "Modelling the anthropogenic impacts on fluvial flood risks in a coastal megacity: a scenario-based case study in Shanghai, China," Landscape and Urban Planning, vol. 136, pp. 144-155, 2015.

[22] J. Yin, D. Yu, Z. Yin, J. Wang, and S. Xu, "Modelling the combined impacts of sea-level rise and land subsidence on storm tides induced flooding of the Huangpu river in Shanghai, China," Climatic Change, vol. 119, no. 3-4, pp. 919-932, 2013.

[23] J. Yin, D. Yu, Z. Yin, J. Wang, and S. Xu, "Multiple scenario analyses of Huangpu river flooding using a $1 \mathrm{D} / 2 \mathrm{D}$ coupled flood inundation model," Natural Hazards, vol. 66, no. 2, pp. 577-589, 2013.

[24] Y. Deng, J. M. Cai, Z. S. Yang, and H. Wang, "Measuring time accessibility with its spatial characteristics in urban areas of Beijing," Acta Geographica Sinica, vol. 67, no. 2, pp. 169-178, 2012, In Chinese.

[25] D. Yu and S. N. Lane, "Urban fluvial flood modelling using a two-dimensional diffusion wave treatment, part 1: mesh resolution effects," Hydrological Processes, vol. 20, pp. 15411565, 2006.

[26] D. Yu and S. N. Lane, "Urban fluvial flood modelling using a two-dimensional diffusion wave treatment, part 2: development of a sub grid-scale treatment," Hydrological Processes, vol. 20, pp. 1567-1583, 2006. 